Individual differences in expectancies for change in depression: Associations with goal pursuit and daily experiences

By: Kari M. Eddington, Chris J. Burgin, and Catherine Majestic

Eddington, K.M., Burgin, C.J., \& Majestic, C. (2016). Individual differences in expectancies for change in depression: Associations with goal pursuit and daily experiences. Journal of Social and Clinical Psychology, 35(8), 628-640. PMCID: PMC5993444

https://doi.org/10.1521/jscp.2016.35.8.629

Individual differences in expectancies for change in depression: Associations with goal pursuit and daily experiences, Kari M. Eddington, Chris J. Burgin, and Catherine Majestic. 2016. Copyright Guilford Press. Reprinted with permission of The Guilford Press.

*** No further reproduction is authorized without written permission from The Guilford Press except for versions made by non-profit organizations for use by the blind or handicapped persons. $* * *$

\begin{abstract}
:
More optimistic expectations for change in patients entering treatment often predict more favorable outcomes. However, our understanding of the nature and function of those expectancies is limited. The current study tested the proposal that optimistic expectancies among patients seeking outpatient psychotherapy for major depressive disorder may be explained in part by having a more adaptive self-regulatory style. A sample of 56 adults $(78.6 \%$ female; mean age 36.5) completed measures of expectancies, depressive symptoms, and aspects of self-regulation. Participants also completed a week of experience sampling using a cell phone system that signaled them eight random times per day for seven days. Results were largely consistent with hypotheses. Depressed participants with more optimistic expectancies had a stronger promotion goal orientation, higher goal re-engagement, and reported greater progress on their most important personal goals; daily positive affect and positive situational appraisals were also higher. Findings may suggest a possible self-regulatory mechanism underlying optimistic expectancies for change.
\end{abstract}

Keywords: expectancies | common factors | self-regulation | goal pursuit | major depressive disorder | psychotherapy

Article:

$* * *$ Note: Full text of article below 


\title{
INDIVIDUAL DIFFERENCES IN EXPECTANCIES FOR CHANGE IN DEPRESSION: ASSOCIATIONS WITH GOAL PURSUIT AND DAILY EXPERIENCES
}

\author{
KARI M. EDDINGTON \\ University of North Carolina at Greensboro \\ CHRIS J. BURGIN \\ Tennessee Tech University \\ CATHERINE MAJESTIC \\ University of North Carolina at Greensboro
}

More optimistic expectations for change in patients entering treatment often predict more favorable outcomes. However, our understanding of the nature and function of those expectancies is limited. The current study tested the proposal that optimistic expectancies among patients seeking outpatient psychotherapy for major depressive disorder may be explained in part by having a more adaptive self-regulatory style. A sample of 56 adults (78.6\% female; mean age 36.5) completed measures of expectancies, depressive symptoms, and aspects of self-regulation. Participants also completed a week of experience sampling using a cell phone system that signaled them eight random times per day for seven days. Results were largely consistent with hypotheses. Depressed participants with more optimistic expectancies had a stronger promotion goal orientation, higher goal re-engagement, and reported greater progress on their most important personal goals; daily positive affect and positive situational appraisals were also higher. Findings may suggest a possible self-regulatory mechanism underlying optimistic expectancies for change.

This research was supported by award number R21MH090414 from the National Institute of Mental Health (trial registration number NCT02134678). The content is solely the responsibility of the authors and does not necessarily represent the official views of the National Institute of Mental Health or the National Institutes of Health.

Address correspondence to Kari M. Eddington, Department of Psychology, P.O. Box 26170, University of North Carolina at Greensboro, Greensboro, NC 27402-6170; E-mail: kmedding@uncg.edu. 
Keywords: expectancies; common factors; self-regulation; goal pursuit; major depressive disorder; psychotherapy

Patients entering treatment vary in their expectancies - that is, the extent to which they anticipate benefitting from the treatment. These expectations are important in understanding how patients approach treatment (Weinberger, Eig, \& Kirsch, 1999) and may explain outcomes such as the placebo effect (Rutherford \& Roose, 2013). Expectancies predict psychotherapy outcomes (Eddington, Dozois, \& Backs-Dermott, 2014; Price, Anderson, Henrich, \& Rothbaum, 2008; Wenzel, Jeglic, Levy-Mack, Beck, \& Brown, 2008; Westra, Dozois, \& Marcus, 2007) and, beyond the treatment context, expectancies are regarded more broadly as critical in understanding how people respond to adversity, such as threats to one's health or well-being (Rasmussen, Wrosch, Scheier, \& Carver, 2006). Although there is a general consensus that expectancies are important, there is a dearth of information on the nature and functional significance of individual differences in expectancies (Arnkoff, Glass, \& Shapiro, 2002; Greenberg, Constantino, \& Bruce, 2006; Meyer et al., 2002).

Variability in expectancies is particularly intriguing when it comes to patients with depression. The cognitive features of depression, such as hopelessness and negative thought patterns, would suggest that expectancies among depressed patients should be uniformly pessimistic. However, variability in expectancies among clinical and nonclinical samples cannot be accounted for by symptom severity alone (Eddington et al., 2014). That is, people with more pessimistic expectancies are not simply those who are more depressed. Given two people with equally severe levels of depression, what is it that makes one person more optimistic about symptom improvement? We propose that a potentially useful framework for understanding these individual differences involves looking at how expectancies are related to individual differences in self-regulation; that is, how people think about and pursue their personal goals.

Mental and physical health problems can be conceptualized from a self-regulatory perspective as threats to the pursuit of personal goals (Rasmussen et al., 2006). If depression, like other physical or behavioral health problems, challenges the capac- 
ity to effectively self-regulate, then optimistic expectancies may stem in part from self-regulatory capacity. In other words, people with a more adaptive and effective self-regulatory style may be better able to weather the storm, resulting in a more optimistic outlook for symptom improvement. Likewise, past experiences with goal success, or current resourcefulness, may be driving expectancies regarding one's coping abilities (Carver \& Scheier, 2000).

What does it mean to be effective or successful in self-regulation? Although an exhaustive review of the topic is beyond the scope of this paper, we selectively discuss several features of goal selection and pursuit that are thought to characterize adaptive self-regulation. First, people who are more effective at self-regulation are better able to define and select goals that are appropriate, such as those that are more concrete and proximal in time. Higher-order, more distal goals are important components of the goal hierarchy (Kelly, Mansell, \& Wood, 2015), but monitoring progress toward them is difficult. Lower-order goals offer more opportunities for detecting progress and, importantly, contribute to the development of self-efficacy (Bandura, 1989), which can foster optimism regarding the chances of goal attainment. Focusing on higher-order meaning-based goals, as opposed to lower-order action-based goals, can disrupt performance (Vallacher, Wegner, \& Somoza, 1989), and evidence suggests that people with depression tend to describe their goals in more abstract terms (Belcher \& Kangas, 2014; Emmons, 1992). Thus, more adaptive self-regulation is defined in part by the ability to identify and pursue goals that are appropriate in scope, resulting in greater perceived progress and more optimism about future success.

Dealing with setbacks and obstacles is a common occurrence in goal pursuit. Flexibility, a second feature of adaptive selfregulation, involves the ability to adjust one's goals in the face of changing circumstances. Letting go of a goal is thought to be adaptive when it leads to re-engagement in new goals (Carver $\&$ Scheier, 2000). Wrosch and colleagues developed a measure of goal adjustment that includes subscales for both disengagement and re-engagement (Wrosch, Scheier, Miller, Schulz, \& Carver, 2003) and found that better goal adjustment is associated with 
higher levels of physical and psychological well-being (Rasmussen et al.; Wrosch, Miller, Scheier, \& de Pontet, 2007; Wrosch et al., 2003). Among depressed individuals, lower goal re-engagement was associated with higher levels of depression symptom severity (Eddington, Silvia, Foxworth, Hoet, \& Kwapil, 2015). Adaptive self-regulation, therefore, involves the ability to flexibly adjust goals.

Although goal progress in general is beneficial for well-being, not all goals result in the same emotional consequences. Rooted in regulatory focus theory (Higgins, 1997), promotion goals are those goals that are concerned with aspirations and advancement. By contrast, prevention goals are concerned with obligations and rules. Promotion-related progress is associated with strong positive affect (e.g., pleasure, pride) while prevention progress is associated with a less intense response (e.g., relief, calm; Higgins, Shah, \& Friedman, 1997). Thus, providing opportunities for positive affect, the pursuit of promotion goals is an important third feature of adaptive self-regulation. This is particularly relevant for individuals with depression, which involves a lack of promotion activation (Strauman, 2002).

To summarize, people who hold more optimistic expectations should show evidence of more adaptive self-regulation. First, they should report more progress on their goals and more success in day-to-day goal-directed activities. Second, they should show greater flexibility in goal pursuit as evidenced by flexible goal adjustment. Third, they should show a stronger orientation toward promotion-type goals. The combination of a stronger promotion focus and a more effective approach to goal setting should also result in greater enjoyment of daily activities and higher daily positive affect. To test these hypothesized relationships, we examined individual differences in expectancies for change in a sample of depressed adults. Participants completed several measures of self-regulation, including goal adjustment, aspects of personal goal pursuit, and promotion/prevention focus, and one week of experience sampling assessing their daily activities and emotions. 


\section{METHOD}

\section{PARTICIPANTS}

Participants were 56 adults (78.6\% female; mean age 36.5, SD $=13.2$ ) seeking treatment for depression. Inclusion criteria included a primary diagnosis of either major depressive disorder (MDD) or dysthymia as confirmed by structured diagnostic interview (see Eddington et al., 2015 for details on recruitment). Of the 56 participants who completed the laboratory questionnaires, one did not complete the experience sampling portion. Of the remaining 55, 96.4\% had MDD and 3.6\% had dysthymia.

\section{MEASURES}

Semi-Structured Clinical Interview for DSM-IV-TR (SCID)—Research Edition (American Psychiatric Association, 2000). The SCID (First, Gibbon, Spitzer, Williams, \& Benjamin, 1997; First, Spitzer, Gibbon, \& Williams, 2002) was used by trained diagnosticians to confirm primary diagnoses.

Depression Change Expectancy Scale. The DCES (Eddington et al., 2014) contains 20 items assessing expectancies for change in depression. It includes optimistically and pessimistically worded items, loading on two correlated subscales, the DCES-O and DCES-P. In the current sample the subscales were highly correlated. ${ }^{1}$ To simplify the results, we reverse-scored the pessimistic items and used a single mean total in which higher scores indicate more optimistic expectancies; internal consistency was excellent (Cronbach's $\alpha=.92)$.

Beck Depression Inventory. The BDI-II (Beck, Steer, \& Brown, 1996) is a widely used self-report measure of depressive symptom severity over the past two weeks. The 21 items are rated on a 4-point scale. The BDI-II has excellent psychometric properties (Dozois \& Covin, 2004), and the internal consistency in this study was good (Cronbach's $\alpha=.84$ ).

1 . In the current sample $r=.76(p<.001)$ for the DCES-P and DCES-O. The overall pattern of results is unchanged when using the single total score compared to the subscale scores. Any exceptions are noted in the results. 
Regulatory Focus Questionnaire. The RFQ (Higgins, Friedman, Harlow, Idson, Ayduk, \& Taylor, 2001) is an 11-item measure of subjective history of success using promotion- and preventionoriented goal attainment. Each item is rated on a 5-point scale, and there are two subscales (Promotion Focus and Prevention Focus). Previous studies have reported good internal consistency (Higgins et al., 2001); in the current study, internal consistency for Promotion was $\alpha=.74$ and $\alpha=.82$ for Prevention.

Goal Adjustment Scale. The GAS (Wrosch et al., 2003) consists of 10 items, four measuring goal disengagement (GAS-D) and six measuring goal re-engagement (GAS-R). The questionnaire instructs the respondents to consider how they usually react when they have to stop pursuing important goals in their lives. Item statements are rated on a 5-point scale, with higher scores indicating better ability to disengage from goals (GAS-D) or to reengage in alternative goals (GAS-R) in the face of failure. Good internal consistency has been reported (Wrosch et al., 2003); in the current study, $\alpha=.82$ for each scale.

Personal Goals Inventory (PGI). This inventory is based in part on Emmons' idiographic measure of personal strivings (Emmons, 1986) and has been used in previous work (Eddington, 2013). Participants generated a list of four important personal goals and were asked to rate each goal as follows: "How difficult is it for you to succeed at this goal?" $(1=$ extremely easy to $5=$ extremely difficult); "How much progress have you made toward this goal?" ( $0=$ none, haven't even tried to $5=$ I've already met this goal); "How important in this goal?" (1 = not very important to 5 = extremely important); and "How likely is it that you will be able to accomplish this goal in the future?" (goal optimism; $1=$ completely unlikely to $7=$ certain). Ratings were averaged across the four goals to produce one mean per item.

Experience Sampling Items. Participants were prompted via cell phone using an automated interactive voice response (IVR) system to complete 32 items assessing different aspects of their experience and situation at the time of the call. For the purposes of the current study, only a subset of items relevant to the hypotheses (i.e., those tapping into experiences of positive and negative 
affect as well as daily activities) were included. Participants entered responses using their mobile phone digital keypad based upon the following instructions:

Please rate the following statements based upon what you were thinking, feeling, and doing at the time of the call from 1 'not at all' to 7 'very much,' with 4 indicating 'somewhat.' It is important that you describe how you were feeling at the moment just before you received the phone call.

Composite variables for positive and negative affect were constructed by calculating means for the five positive affect items and seven negative affect items, respectively.

\section{PROCEDURES}

Participants provided informed consent in compliance with Institutional Review Board standards, completed the BDI-II, and (if the BDI-II score was above 14) completed relevant portions of the SCID. Experimenters explained the ESM procedures, including an overview of how to use the IVR system (Telesage; www. telesage.com) with their own phone or one provided to them. Participants designated a 12-hour window that they preferred to receive calls. ESM data collection employed random-time sampling eight times each day for one week. The calls were randomized within 90 minute segments equally separated within each 12-hour block. If a participant missed a call, he or she could call the system back within a restricted 10-minute period, and responses were all date- and time-stamped.

\section{ESM ANALYTIC APPROACH}

Given the nested structure of the ESM data, we used multilevel modeling to test hypotheses about the relationship between expectancies and daily experiences. We estimated the multilevel models with HLM 7, using restricted maximum likelihood with robust standard errors. All items were modeled as continuous; unless noted otherwise, all effects are unstandardized. BDI-II 
scores were included along with DCES scores in all models in order to examine the unique contribution of expectancies. The response rate for the experience sampling surveys in this study was good and in line with previous studies (Bylsma, TaylorClift, \& Rottenberg, 2011; Havermans, Nicolson, \& deVries, 2007; Myin-Germeys et al., 2003). Of the 56 possible calls, participants completed on average $72.23 \%(M=40.45$ calls completed, $S D=$ 14.34, $\operatorname{Min} / \operatorname{Max}=6,58)^{2}$

\section{RESULTS}

Correlations between single-time-point measures of self-regulatory style (including regulatory focus, aspects of personal goal pursuit from PGI ratings, and goal adjustment) and DCES scores are shown in Table 1. Across the sample, the mean on the DCES was $3.46(S D=.62)$, suggesting that participants on average were neutral (neither very optimistic nor pessimistic) about the possibility of their depression improving. As expected, there was a modest but significant negative correlation between expectancies and BDI-II scores. Consistent with our hypotheses, higher DCES scores (reflecting more optimistic expectancies) were significantly associated with stronger promotion focus, higher goal re-engagement (but not disengagement), greater goal progress, and greater optimism about goal attainment.

Results from the multilevel models using the ESM data are shown in Table 2. BDI-II scores significantly predicted daily negative, but not positive, affect levels. Consistent with hypotheses, more optimistic expectancies predicted higher levels of daily positive affect. Of the four items concerning current activities, only the item concerning appraisals of the current situation being positive was significantly associated with expectancies.

\section{DISCUSSION}

We began with the proposal that individual differences in expectancies for change in depression may be attributable in part

2. Due to a technical error, one participant received and completed two extra calls; that participant's response rate was calculated as $100 \%$ and we included all responses in the analyses. 
TABLE 1. Bivariate Correlations Between Expectancy Scale (DCES) Scores, Depressive Symptoms, and Self-Regulation $(N=55)$

\begin{tabular}{lccc}
\hline & $\boldsymbol{M}, \boldsymbol{S} \boldsymbol{D}$ & Correlation with DCES & $\boldsymbol{p}$ \\
\hline BDI-II & $34.68,8.07$ & -.27 & $<.05$ \\
Promotion & $18.54,4.16$ & .64 & $<.001$ \\
Prevention & $18.95,5.15$ & .03 & $>.05$ \\
Goal disengagement & $11.89,3.50$ & -.06 & $>.05$ \\
Goal re-engagement & $19.61,4.00$ & .58 & $<.001$ \\
PGl importance & $4.42,0.43$ & .20 & $>.05$ \\
PGl difficulty & $2.04,0.51$ & .23 & $>.05$ \\
PGl progress & $2.92,0.74$ & .30 & $<.05$ \\
PGl optimism & $4.61,1.09$ & .35 & $<.001$ \\
\hline
\end{tabular}

Note: DCES = Depression Change Expectancy Scale; PGI = Personal Goals Inventory

to self-regulatory capacity and efficacy. This study involved a clinically depressed community-based sample of adults whose depression was, on average, in the low end of the severely depressed range. Most of the participants had received prior treatment and had experienced multiple prior episodes of depression, and yet there was substantial variability in expectancies. Depression severity was significantly correlated with expectancies but only modestly so, consistent with previous findings (Eddington et al., 2014) and with the notion that optimistic expectancies cannot be explained solely by depression severity.

We found partial support for our first hypothesis, which was that more optimistic expectancies should be associated with more progress on personal goals and more success in day-to-day goal-directed activities. Participants' ratings of progress on their four most important personal goals were significantly positively correlated with DCES scores. However, daily ratings of success in activities were not related to expectancies. One possible explanation for this inconsistency is that the daily activity ratings were not restricted to activities in the service of important personal goals. Therefore, although these activities are serving some motivational function, they may not always be connected to a higher-order, meaningful goal.

Our second hypothesis regarding the relationship between expectancies and goal adjustment was also partially supported. We found that more optimistic expectancies were associated with higher re-engagement but not disengagement. Disengage- 
TABLE 2. Results from Multilevel Models Examining Expectancies (DCES scores) and BDI-II as Predictors of Experiences in Daily Life $(N=55)$

\begin{tabular}{lcccccccc}
\hline & \multicolumn{3}{c}{ DCES } & & \multicolumn{3}{c}{ BDI-II } \\
\cline { 2 - 3 } Level 1 Variables & $\boldsymbol{B}$ & $\boldsymbol{S E}$ & $\boldsymbol{p}$ & & $\boldsymbol{B}$ & $\boldsymbol{S E}$ & $\boldsymbol{p}$ \\
\hline Daily Affect & & & & & & & \\
Positive Affect & 0.93 & 0.12 & $<.001$ & -.00 & .01 & .55 \\
Negative Affect & -0.21 & 0.16 & .20 & .04 & .01 & $<.001$ \\
Daily Activities and Event Appraisals & & & & & & \\
I like what I'm doing & 0.11 & 0.17 & $>.05$ & -.01 & .01 & .59 \\
Success in current activity & 0.23 & 0.20 & $>.05$ & -.00 & .02 & .86 \\
Current situation is positive & 0.42 & 0.21 & $<.05$ & -.01 & .01 & .74 \\
Current situation is stressful & -0.12 & 0.24 & $>.05$ & .04 & .02 & $<.05$ \\
\hline
\end{tabular}

Note: DCES = Depression Change Expectancy Scale

ment from unattainable goals is thought to be adaptive only in the presence of re-engagement (Carver \& Scheier, 2000), suggesting that re-engagement may be a more important component of flexibility in goal adjustment. We have proposed previously that goal disengagement in the context of depression may take on a different meaning (i.e., premature giving up) and therefore may not serve an adaptive function (Eddington et al., 2015).

Our third set of hypotheses concerned the relationship between expectancies and promotion-type goal pursuit as well as the emotional consequences thereof. Consistent with our predictions, depressed individuals with more optimistic expectancies were indeed more strongly orientated toward promotion-type goals. In addition, more optimistic expectancies were associated with higher daily reports of positive affect and with more positive appraisals of the current situation. Although we did not have a direct measure of the extent to which participants set more adaptive goals (i.e., more proximal and less abstract goals, allowing for more frequent detection of progress), one interpretation of this finding is that the combination of promotion construal and more adaptive goal selection may lead to greater opportunities for positive emotional events. We note, however, that expectancies were unrelated to the level of enjoyment or success in current daily activities and were also unrelated to goal difficulty. This suggests that people with more optimistic expectan- 
cies are not simply setting easier goals or pursuing activities that are more fun.

In conclusion, the results from this study largely supported the primary hypotheses, suggesting that individual differences in expectancies for change in depression may be a reflection of the capacity to self-regulate. Depressed adults with more optimistic expectancies are more promotion-oriented, report more progress on their important personal goals, report higher goal reengagement, experience greater daily positive affect, and make more positive daily event appraisals. One limitation of this study concerns the generalizability of the results. This sample of treatment-seeking individuals may be more motivated, and more optimistic about improvement, than those who are not seeking treatment. A second limitation is the reliance on correlational data, which does not allow us to tease apart questions about causality in the development of expectancies and self-regulatory variables. However, despite the limitations these finding suggest that this line of inquiry may be a fruitful one. For example, there is evidence that both expectancies and self-efficacy change in similar, but not identical, ways throughout the course of therapy (Brown et al., 2014), suggesting that interventions targeting both might lead to enhanced treatment outcomes.

\section{REFERENCES}

American Psychiatric Association. (2000). Diagnostic and statistical manual of mental disorders (4th ed.-text revision). Washington, DC: American Psychiatric Publishing, Inc.

Arnkoff, D. B., Glass, C. R., \& Shapiro, S. J. (2002). Expectations and preferences. In J. C. Norcross \& J. C. (Ed), Psychotherapy relationships that work: Therapist contributions and responsiveness to patients. (pp. 335-356). New York: Oxford University Press.

Austin, J. T., \& Vancouver, J. B. (1996). Goal constructs in psychology: Structure, process, and content. Psychological Bulletin, 120, 338-375. doi:10.1037/00332909.120.3.338

Bandura, A. (1989). Self-regulation of motivation and action through internal standards and goal systems. In L. A. Pervin (Ed), Goal concepts in personality and social psychology. (pp. 19-85). Hillsdale, NJ: Lawrence Erlbaum.

Beck, A. T., Steer, R. A., \& Brown, G. K. (1996). Manual for the Beck Depression Inventory-II. San Antonio, TX: Psychological Corporation. 
Belcher, J., \& Kangas, M. (2014). Reduced goal specificity is associated with reduced memory specificity in depressed adults. Cognition and Emotion, 28, 163-171. doi:10.1080/02699931.2013.807776

Brown, L. A., Wiley, J. F., Wolitzky-Taylor, K., Roy-Byrne, P., Sherbourne, C., Stein, M. B., . . . Craske, M. G. (2014). Changes in self efficacy and outcome expectancy as predictors of anxiety outcomes from the CALM study. Depression and Anxiety, 31, 678-689. doi:10.1002/da.22256

Bylsma, L. M., Taylor-Clift, A., \& Rottenberg, J. (2011). Emotional reactivity to daily events in major and minor depression. Journal of Abnormal Psychology, 120, 155-167. doi:10.1037/a0021662

Carver, C. S., \& Scheier, M. F. (1990). Origins and functions of positive and negative affect: A control-process view. Psychological Review, 97, 19-35.

Carver, C. S., \& Scheier, M. F. (2000). Scaling back goals and recalibration of the affect system are processes in normal adaptive self-regulation: understanding "response shift" phenomena. Social Science \& Medicine, 50, 1715-1722. doi:10.1016/S0277-9536(99)00412-8

Dozois, D. J. A., \& Covin, R. (2004). The Beck Depression Inventory-II (BDI-II), Beck Hopelessness Scale (BHS), and Beck Scale for Suicide Ideation (BSS). In M. J. Hilsenroth \& D. L. Segal (Eds.), Comprehensive handbook of psychological assessment: Vol. 2: Personality assessment (pp. 50-69). Hoboken, NJ: Wiley.

Eddington, K. M. (2013). Perfectionism, goal adjustment, and self-regulation: A short-term follow-up study of distress and coping. Self and Identity, 13, 197213. doi:10.1080/15298868.2013.781740

Eddington, K. M., Dozois, D.J.A., \& Backs-Dermott, B. J. (2014). Evaluation of the internal consistency, factor structure, and validity of the Depression Change Expectancy Scale. Assessment, 21, 607-617. doi:10.1177/1073191113517929

Eddington, K. M., Silvia, P. J., Foxworth, T. E., Hoet, A., \& Kwapil, T. R. (2015). Motivational deficits differentially predict improvement in a randomized trial of self-system therapy for depression. Journal of Consulting and Clinical Psychology, 83, 602-616. doi:10.1037/a0039058

Emmons, R. A. (1986). Personal strivings: An approach to personality and subjective well-being. Journal of Personality and Social Psychology, 51, 1058-1068.

Emmons, R. A. (1992). Abstract versus concrete goals: Personal striving level, physical illness, and psychological well-being. Journal of Personality and Social Psychology, 62, 292-300.

First, M. B., Gibbon, M., Spitzer, R. L., Williams, J.B.W., \& Benjamin, L. S. (1997). Structured Clinical Interview for DSM-IV Axis II Personality Disorders (SCIDII). Washington, DC: American Psychiatric Press.

First, M. B., Spitzer, R. L., Gibbon, M., \& Williams, J.B.W. (2002). Structured Clinical Interview for DSM-IV-TR Axis I Disorders. New York: Biometrics Research, New York State Psychiatric Institute.

Greenberg, R. P., Constantino, M. J., \& Bruce, N. (2006). Are patient expectations still relevant for psychotherapy process and outcome? Clinical Psychology Review, 26, 657-678. 
Havermans, R., Nicolson, N. A., \& deVries, M. W. (2007). Daily hassles, uplifts, and time use in individuals with bipolar disorder in remission. Journal of Nervous and Mental Disease, 195, 745-751. doi:10.1097/NMD.0b013e318142cbf0

Higgins, E. T. (1987). Self-discrepancy: A theory relating self and affect. Psychological Review, 94, 319-340.

Higgins, E. T. (1997). Beyond pleasure and pain. American Psychologist, 52, 1280 1300.

Higgins, E. T., Friedman, R. S., Harlow, R. E., Idson, L. C., Ayduk, O. N., \& Taylor, A. (2001). Achievement orientations from subjective histories of success: Promotion pride versus prevention pride. European Journal of Social Psychology, 31, 3-23.

Higgins, E. T., Shah, J., \& Friedman, R. (1997). Emotional responses to goal attainment: Strength of regulatory focus as moderator. Journal of Personality and Social Psychology, 72, 515-525.

Kelly, R. E., Mansell, W., \& Wood, A. M. (2015). Goal conflict and well-being: A review and hierarchical model of goal conflict, ambivalence, self-discrepancy and self-concordance. Personality and Individual Differences, 85, 212-229. doi:10.1016/j.paid.2015.05.011

Meyer, B., Pilkonis, P. A., Krupnick, J. L., Egan, M. K., Simmens, S. J., \& Sotsky, S. M. (2002). Treatment expectancies, patient alliance and outcome: Further analyses from the National Institute of Mental Health Treatment of Depression Collaborative Research Program. Journal of Consulting and Clinical Psychology, 70, 1051-1055.

Myin-Germeys, I., Peeters, F., Havermans, R., Nicolson, N. A., deVries, M. W., Delespaul, P., \& van Os, J. (2003). Emotional reactivity to daily life stress in psychosis and affective disorder: An experience sampling study. Acta Psychiatrica Scandinavica, 107, 124-131. doi:10.1034/j.1600-0447.2003.02025.x

Price, M., Anderson, P., Henrich, C. C., \& Rothbaum, B. O. (2008). Greater expectations: Using hierarchical linear modeling to examine expectancy for treatment outcome as a predictor of treatment response. Behavior Therapy, 39, 398-405.

Rasmussen, H. N., Wrosch, C., Scheier, M. F., \& Carver, C. S. (2006). Self-regulation processes and health: The importance of optimism and goal adjustment. Journal of Personality, 74, 1721-1747. doi:10.1111/j.1467-6494.2006.00426.x

Rutherford, B. R., \& Roose, S. P. (2013). A model of placebo response in antidepressant clinical trials. The American Journal of Psychiatry, 170, 723-733.

Strauman, T. J. (2002). Self-regulation and depression. Self and Identity, 1, 151-157.

Vallacher, R. R., Wegner, D. M., \& Somoza, M. P. (1989). That's easy for you to say: Action identification and speech fluency. Journal of Personality and Social Psychology, 56, 199-208. doi:10.1037/0022-3514.56.2.199

Weinberger, J., Eig, A., \& Kirsch, I. (1999). Expectancies: The ignored common factor in psychotherapy. In I. Kirsch (Ed.), How expectancies shape experience (pp. 357-382). Washington, DC: American Psychological Association. doi:10.1037/10332-015 
Wenzel, A., Jeglic, E. L., Levy-Mack, H. J., Beck, A. T., \& Brown, G. K. (2008). Treatment attitude and therapy outcome in patients with borderline personality disorder. Journal of Cognitive Psychotherapy, 22, 250-257.

Westra, H. A., Dozois, D.J.A., \& Marcus, M. (2007). Expectancy, homework compliance, and initial change in cognitive-behavioral therapy for anxiety. Journal of Consulting and Clinical Psychology, 75, 363-373.

Wrosch, C., Dunne, E., Scheier, M. F., \& Schulz, R. (2006). Self-regulation of common age-related challenges: Benefits for older adults' psychological and physical health. Journal of Behavioral Medicine, 29, 299-306. doi:10.1007/ s10865-006-9051-x

Wrosch, C., Miller, G. E., Scheier, M. F., \& de Pontet, S. B. (2007). Giving up on unattainable goals: Benefits for health? Personality and Social Psychology Bulletin, 33, 251-265.

Wrosch, C., Scheier, M. F., Miller, G. E., Schulz, R., \& Carver, C. S. (2003). Adaptive self-regulation of unattainable goals: Goal disengagement, goal reengagement, and subjective well-being. Personality and Social Psychology Bulletin, 29, 1494-1508. 
Reproduced with permission of the copyright owner. Further reproduction prohibited without permission. 